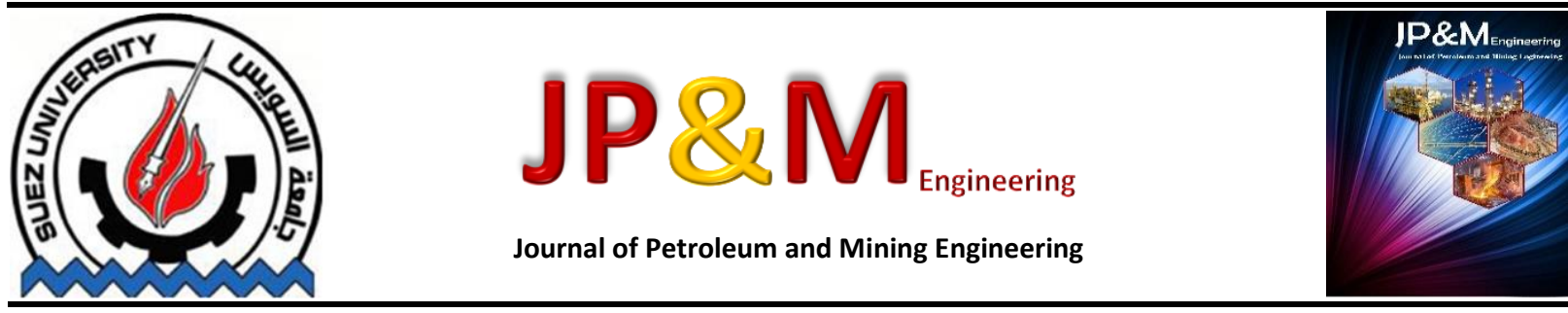

\title{
An Investigation of Damages in Low Power Wind Turbine Blades
}

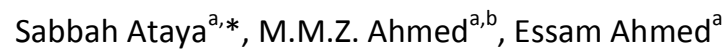 \\ ${ }^{\mathrm{a}}$ Department of Metallurgy and Materials Eng., Faculty of Petroleum and Mining Eng., Suez University, Suez, Egypt. \\ ${ }^{\mathrm{b}}$ The British University in Egypt \\ *Corresponding author sabbah.ataya@suezuniv.edu.eg
}

\section{Keywords}

Fiber glass reinforced polymer wind turbine blades,

discontinuities; damages; VT inspection; NDT

\begin{abstract}
Data in the literature about the various types of damages in wind turbines which may result during manufacturing or operation is not enough. In the current work, a number of 18 blades of $300 \mathrm{~kW}$ and 81 blades of $100 \mathrm{~kW}$ power wind turbines are inspected using visual test (VT) and if needed using liquid penetrant test (PT) when needed. The location and size of discontinuities found are measured and documented. Types of discontinuities are categorized into four main groups: 1) Transverse cracks and longitudinal cracks, 2) Hair line surface cracks, coating pores, surface damages, holes or penetrations, 3) Edge cuts or crushing and side separation, and 4) reworked areas. The gathered data are analyzed to allocate the different forms of discontinuities about the blade length, to establish an indication of the rotor blades working conditions. It is found that the transverse carks are concentrated at the highly loaded and geometric change region of trailing edge. Longitudinal cracks up to $59 \mathrm{~cm}$ long are detected also at the region of the geometric change; i.e. in the root and the cover of the aerodynamic zone. Edge damages such as edge cuts or crushing and partial side separation are found in the sharp trailing edge. Surface and coating damages are observed on the leading edge due to erosion.
\end{abstract}

\section{Introduction}

Blades are the most critical parts in the wind turbines which are difficult and expensive to be replaced. Periodical inspection of the wind turbine blades is very important for early detection of any serious damage, treating of which increases the life time of the wind turbine. Although the designed life time of wind turbines is usually 20 years, visual inspection has revealed critical damages after only five years (a total of $7.13 \times 106$ cycles) in inspected blades of $300 \mathrm{~kW}$ turbines produced by hand lay-up $[1,2]$. The presence of mechanically caused discontinuities in the blade material subjected to weathering conditions causes a damaging effect on the fiberglass reinforced resin even if this effect is difficult to assess [3]. In the literature there is no much data available about the various forms of damages that may result either due to manufacturing problems or due to operating service conditions Thus, the aim of the current work is to carry out a systematic inspection of wind turbine blades with a life time ranging between 18 and 21 years. The various discontinuities and damages will be documented, classified, measured and allocated on the blade rotor radius. The possible root causes of such damages will be discussed. In previous work [4] a part from these discontinuities were discussed in concentration on the faced damages in trailing edge of the blade.

\section{Inspection Procedures and Techniques}

In this study, a number of 18 blades of $300 \mathrm{~kW}$ and 81 blades of $100 \mathrm{~kW}$ wind turbines were subjected to visual inspection test (VT) and some of which were inspected by liquid penetrant test (PT). The blade lengths are $9.5 \mathrm{~m}$ and $14.2 \mathrm{~m}$ for the 100 and $300 \mathrm{~kW}$ turbines, respectively. Before VT testing, the blades have been washed and cleaned thoroughly with a brush using water and soap. The blasé under investigation has been given a designation name then a scale tape was attached to the investigated blade side to which the location of any discontinuity or damage is refereed. The inspection was carried out through two strokes; from the tail up to the hub on the trailing edge first then the leading edge of the blade. A digital camera was used to record discontinuities. The PT test was applied according to the standard technique given in $[5,6]$, to reveal fine cracks. 


\section{Results and Discussion}

\section{Life time of the inspected wind turbines}

The inspected wind turbines are located in Hurghada, Egypt. The average wind speed in this area is ranging between $3.05 \mathrm{~m} / \mathrm{s}$ and $11.11 \mathrm{~m} / \mathrm{s}$ with an average speed of $6.9 \mathrm{~m} / \mathrm{s}$. The maximum temperature is ranging between $34.4^{\circ} \mathrm{C}$ and $42.2^{\circ} \mathrm{C}$ in summer and the lowest temperature is ranging between $7.8^{\circ} \mathrm{C}$ and $18.9^{\circ} \mathrm{C}$ in winter. Due to the plan nature of the ground in this area, only mild sand storm could be found. The life time of the wind turbines ranges between 18 and 21 years. The actual working life (in cycles) of each turbine is calculated on basis of the operation data (No. of cycles per minute RPM), life in year and the capacity factor of each turbine type. A capacity factor of 0.22 and 0.25 , and a number of revolutions per minute of 33 and $38 \mathrm{rpm}$ were used for the 100 and $300 \mathrm{~kW}$ turbines, respectively. The turbine operation value is given as number of cycles till the time of inspection and is found between $0.7 \times 10^{8}$ and $1.16 \times 10^{8}$ cycles, as illustrated in Error! Reference source not found.. The working number of cycles is consistent with published data [7].

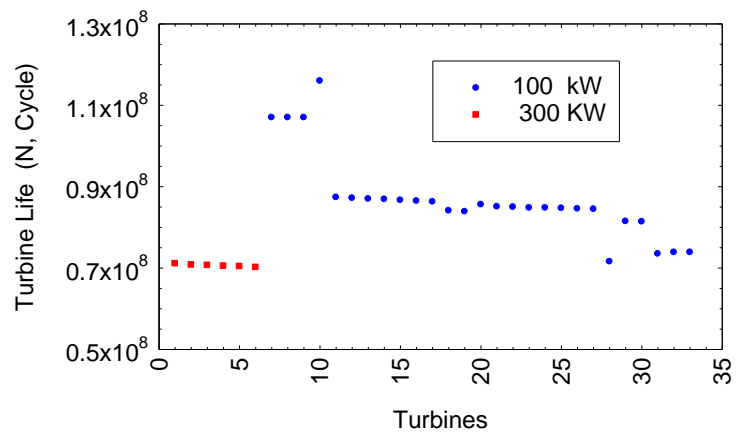

Figure 1 Wind turbine lives described as number of cycles against the wind turbine number for the inspected wind turbine (1 to 33 ).

\section{Forms of discontinuities or damages}

Extensive analysis of recorded pictures has been carried out to determine the type, size and location of discontinuities or damages. The total number of discontinuities and damages in inspected blades is 1003, which could be categorized into:

- Longitudinal cracks and transverse cracks,

- Trailing edge cuts or crushing,

- Surface or coating damages, which are classified according to their size into pin holes or pores (up to $2 \mathrm{~mm}$ diameter) and larger coating damage (more than $3 \mathrm{~mm}$ diameter), holes or penetration with depth up to $13 \mathrm{~mm}$, and hair line surface cracks, and

- Reworked areas.

Because the number of blades (B) and the blade length $\left(R_{0}\right)$ of both inspected turbine types is different, the number of discontinuities $(N)$ is normalized and expressed in terms of number per blade unit length using this equation:

$$
n=\frac{N}{B \cdot R_{0}}
$$

where, the number of the inspected blades $B$ is 18 and 81 and the blade length $R_{o}$ is $14.2 \mathrm{~m}$ and 9.5 $\mathrm{m}$ for 300 and $100 \mathrm{~kW}$ power turbines, respectively. Figure 2 illustrates the number of discontinuities per unit length of a blade for both 100 and $300 \mathrm{~kW}$ power wind turbines. Clearly, it can be observed that the number of discontinuities per blade length is higher in the $300 \mathrm{~kW}$ wind turbine than in the 100 $\mathrm{kW}$ wind turbine in case of the longitudinal cracks, edge cuts and coating damage. This trend is reversed for the other types of discontinuities.diagenetic process.

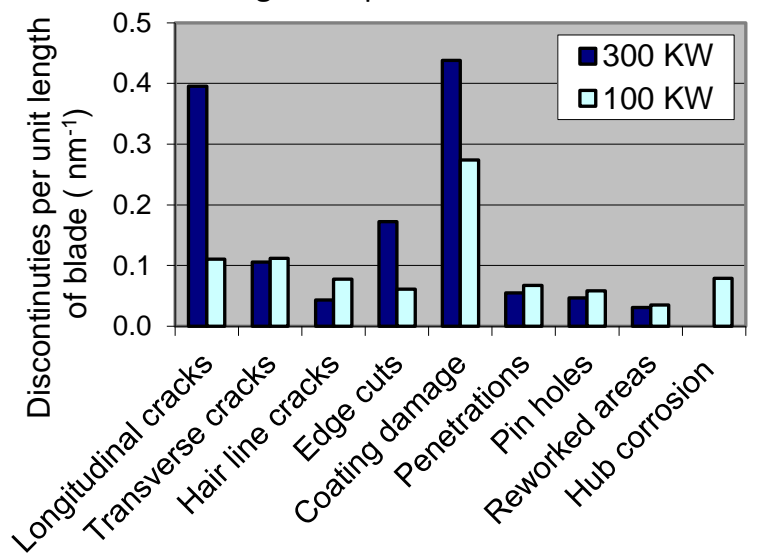

Figure 2 Number of discontinuities per unit length of the blades of 100 and $300 \mathrm{~kW}$ turbines.

A wind turbine blade consists of two glued together individual shells produced by hand lay-up technique. Error! Reference source not found.-a shows a schematic representation of the wind turbine blade structure. The blade is protected from ultraviolet degradation and water penetration by a gelcoat. A main carrying spar made from fiberglass reinforced resin supports the two shells and strengthens the whole structure. Spar in the form of box is used in the inspected $100 \mathrm{~kW}$ and $300 \mathrm{~kW}$ blades. Error! Reference source not found.-b shows a section at $4 \mathrm{~m}$ from the root of the $100 \mathrm{~kW}$ blade.

Understanding the production method of the wind turbine blades $[2,9,10]$ and the working conditions helps in estimation of the mutual effect of the different defects from the production or the working conditions on the formation of various discontinuities. Because, it is impossible to repeat the same defects for further failure analysis, the failure root causes are estimated on the basis of the background of the production technique and the possible formation of certain defects at certain positions and through the comparison with similar published damages [1]. 


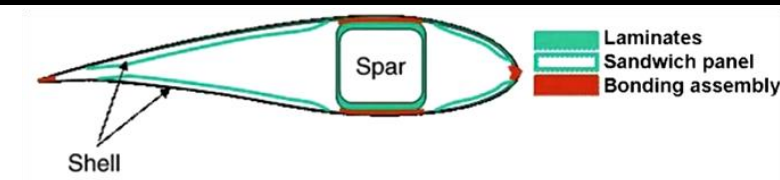

(a)

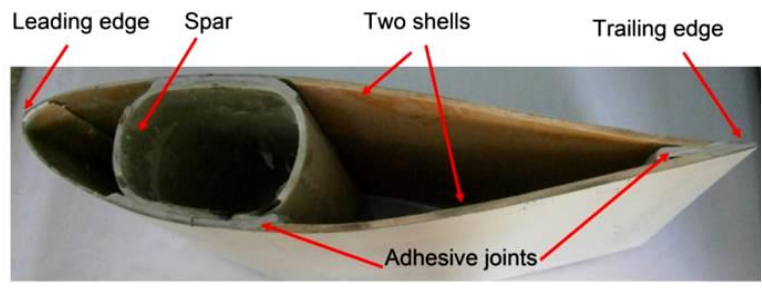

(b)

Figure 3 a) Section in a wind turbine bade [8] and section in a $100 \mathrm{~kW}$ blade at $40 \mathrm{~m}$ from the root.

The effect of severe working conditions during this long working time also contributes to the causes of damage. During this long time, the rotor blades are exposed to extreme temperatures (from 7.8 to $42.4^{\circ} \mathrm{C}$ ), humidity, rain, solar radiation and salinity. In the following section, some examples for each type of discontinuities or damages is illustrated and discussed, the flaw size and its allocation on the rotor radius are presented and the possible causes of failure are explained.

\section{Cracks}

\section{Longitudinal Cracks}

Longitudinal cracks (LCs) are parallel to blade length. Error! Reference source not found. (a-c) shows some examples of LCs in 100 and $300 \mathrm{~kW}$ rotor blades. Relatively long LCS are observed at the root or in the cover of the aerodynamic zone. The longest LC (60 cm long) shown in Error! Reference source not found.-a is found at the transition zone, where abrupt change of material thickness exists [11]. Error! Reference source not found.-b shows an LC located at $2.85 \mathrm{~m}$ away from the blade tip of 300 $\mathrm{kW}$ turbines and grows in the bonding layer of the two shell halves. Moreover the LC in Error! Reference source not found.-c is accompanied with some damages and removal of the gelcoat on both sides of the crack.

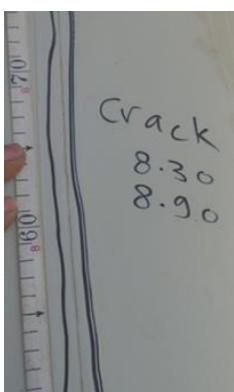

(a)

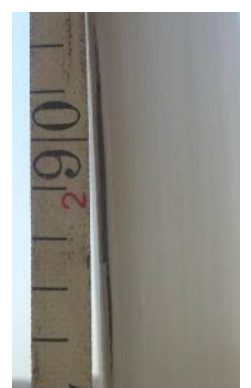

(b)

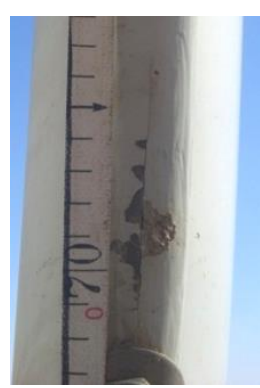

(c)
Figure 4 Examples of longitudinal cracks found in the blades of $100 \mathrm{~kW}$ (a and c) and (b) $300 \mathrm{~kW}$ wind turbines.

Error! Reference source not found. illustrates the distribution of LCs sizes along the blade length.
In this figure the blade length has been normalized by dividing the crack location ( $R$ ) by the blade length (RO) to represent the data obtained from both types of wind turbine blades (100 and $300 \mathrm{~kW})$. It can be observed that in the $100 \mathrm{~kW}$ wind turbine blades the majority of LCs is located near the hub of the blade root and in the cover of the aerodynamic zone [1]. In contrast, in the $300 \mathrm{~kW}$ wind turbine blades, the majority of LCs is located near the tip of the blade (Error! Reference source not found.). The number of LCs per blade unit length is higher in the blades of the $300 \mathrm{~kW}$ turbines, as shown in Error! Reference source not found.. The cracks length varies from few centimeters to about $40 \mathrm{~cm}$. The length of one crack in the $300 \mathrm{~kW}$ turbines reaches a value of $135 \mathrm{~cm}$. The depth of LCs is determined using a $0.05 \mathrm{~mm}$ thin filler sheet. Some of the cracks are up to a depth of $10 \mathrm{~mm}$ in the middle of long LCs, while on the rear thirds it hardly reaches a depth of just $5 \mathrm{~mm}$.

The distribution of the discontinuities on the blade length (Error! Reference source not found.) implies a frequent occurrence of LCs near the root of the $100 \mathrm{~kW}$ blades, while the frequent occurrence of LCs in the $300 \mathrm{~kW}$ blades is at the lower third (near the tip).

The main causes of LCs either near the blade tip or near the hub could be contributed either from the manufacturing process or from the operating conditions. The blade is made of two half shells joined together with about $1 \mathrm{~cm}$ thick bonding material at the trailing edge, Error! Reference source not found.. The shell thickness decreases from the root to the tip. The thickness was found to change from 17 to $27 \mathrm{~mm}$ near the blade root of an equivalent $300 \mathrm{~kW}$ wind turbine [1]. Moreover the shell thickness decreases gradually towards the tip, causing a required decrease of rigidity towards the tip. The drawback of low rigidity of the rare third of the blade is the increased deflection leading to high shear stresses at the interface between the rotor shell and the bonding materials. This can lead to decohesion or cracks at the trailing edge bonds, which is probably the reason of LCs found near to the tip (Error! Reference source not found.-b).

Also, during joining of the two shell halves, two types of defects may occur. One can be called "oversum" when excess bonding material exists and the other can be called "undersum" when unfilled spaces between the two shell halves exist. Oversum defects at the shell edges are treated by grinding while undersum defects are filled by bonding material. The abrupt change of material thickness at the root and the aerodynamic cover of the blade leads to similar damages in $300 \mathrm{~kW}$ turbine blades [1], which could be classified as fatigue damage. The reason for the existence of LCs at the root and cover of the aerodynamic zone (Error! Reference source not found.-a) could be due to the interaction of fatigue loading and geometric change of the blade, which increases the severity of stresses [12]. Such 
LCs should be structurally repaired to extend the life of the working blades.

\section{Transverse Cracks}

Transverse cracks (TCs) grow perpendicular to the blade axis. TCs are observed mainly on the blade trailing edge of the 100 and $300 \mathrm{~kW}$ wind turbines. Error! Reference source not found. (a-c) shows some examples of transverse cracks, observed in the 100 and $300 \mathrm{~kW}$ penetrating the trailing edge with lengths up to $4 \mathrm{~cm}$. TCs are divided into four types, namely simple, round, short root and repeated simple TCs.

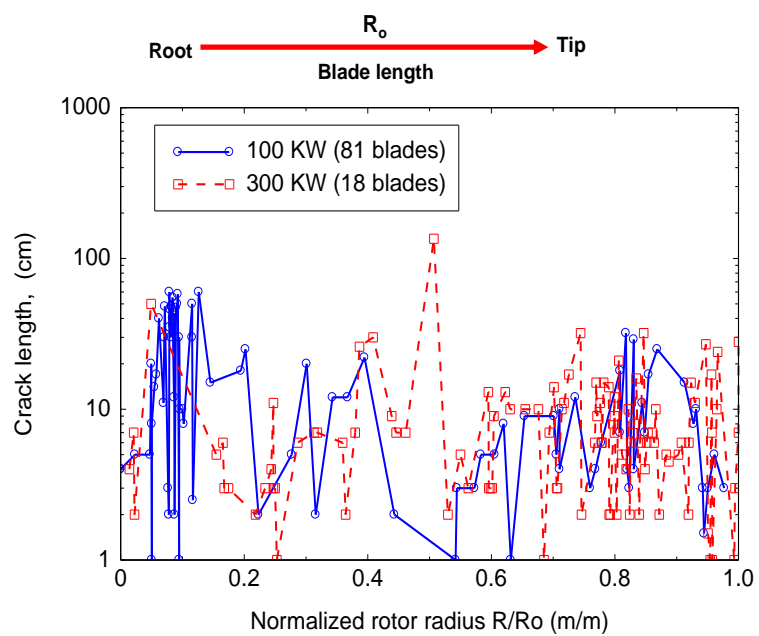

Figure 5 Distribution of longitudinal crack length along the normalized rotor radius for 100 and $300 \mathrm{~kW}$ wind turbines.

a. Simple TCS grow only in one side of the blade i.e., only in one shell half, mainly at the trailing edge and stop at the edge of the blade. An example of such cracks in the $100 \mathrm{~kW}$ wind turbine is shown in Error! Reference source not found. a. On assembly of shell halves some misalignment could occur, and should be corrected by grinding one side of the trailing edge. This can reduce the reinforcing fiberglass, weakens the edge under high loading condition and leads to initiation of such cracks. The straight end of the simple crack (Error! Reference source not found.-a) indicates that the resistance from the reinforcing fiber is limited and in could grow further.

$b$ Round TCs grow on both sides of the trailing edge of the blade i.e., through both shell halves of the blade. An example of round TCs found in the $300 \mathrm{~kW}$ wind turbine is shown in (Error! Reference source not found. b-c). Such crack has a branched river form, due to crack growth obstacles formed from the fiber layers. A round TC can start as a simple TC. Then it can grow further by crossing the trailing edge to the other side. The possible causes of round TCs could be the weak reinforcing at this region, as mentioned earlier. Extensive investigation is needed to examine the presence of enough reinforcement at the trailing edge. Over loading during service can also be a reason of occurrence of round TCs.
Round transverse crack is considered one of the most dangerous cracks, as it crosses the highly loaded edge of the blade. A follow-up inspection plan is designed to monitor the progress of round TCs.

c. Short root TCS are shallow and short (1.5 up to $2.5 \mathrm{~cm})$ and are located between the black line marks in Error! Reference source not found.-a. These cracks are found in the blade root of the 100 $\mathrm{kW}$ wind turbine. These short root TCs are found as individual cracks or as a group of up to 7 neighboring cracks with 2 to $6 \mathrm{~cm}$ inter-crack spacing. These repeated short TCs could be due to excessive cosmetic bonding material to fill any undersum and to treat any geometrical error to get round cylindrical root.

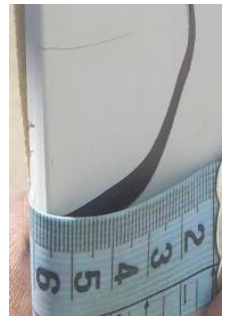

a) Simple TC at 3.4 $\mathrm{m}$ from the tip

$(100 \mathrm{~kW})$

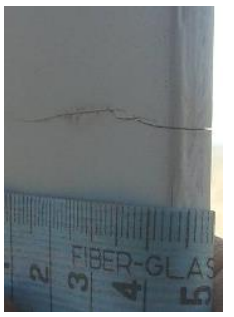

b) Round TC at $2.6 \mathrm{c}$ ) $\mathrm{m}$ from hub $(300 \mathrm{~kW})$

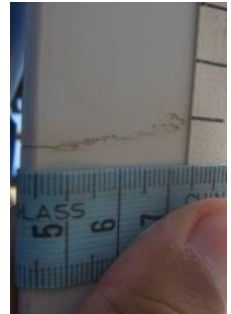

tehr side of the crack in (b) (300 kW)
Figure 6 Examples of simple and round transverse cracks in 300 and $100 \mathrm{~kW}$ wind turbines.

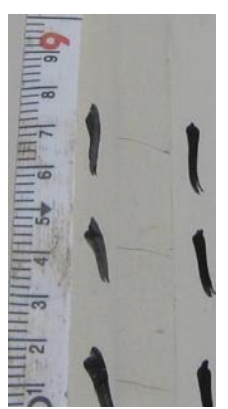

a) Trailing edge TCs at $45^{\circ}$ $(300 \mathrm{~kW})$

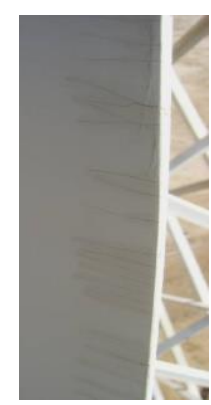

b) Repeated TCs from at

$3.05-5.05 \mathrm{~m}$

(300 kW)

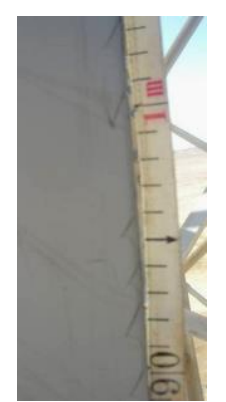

c) Short root TCs $(100 \mathrm{~kW})$
Figure 7 Different forms of repeated TCs in the blades of 300 and $100 \mathrm{~kW}$ wind turbines.

d. Repeated simple TCs are found on one side of the trailing edge, as shown in Error! Reference source not found.-b, in only one blade of the 300 kW wind turbine. These TCs are mainly superficial and at most it extends to just under the coating layer. This type of cracks could be either due to impact force on the trailing edge from the other side, or due to the stall of the blade. Wind turbine blade stalling is an edgewise vibration [12] due to increasing the angle at which the wind strikes the blade (angle of attack), as shown in Error! Reference source not found.-b, and it reduces the induced drag (drag associated with lift). Stalling happens at higher wind speed. If the blade flat side faces directly the wind full stalling (blade stops) may 
take place. Stalling is not frequent to occur in this wind farm.

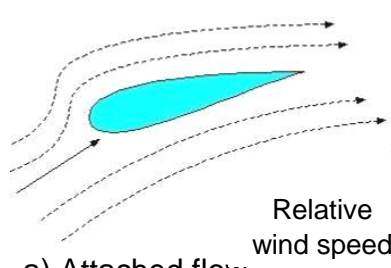

a) Attached flow

wind speed
Figure 8 Position of the wind turbine relative to the wind current: a) attached flow and b) stall [12-14].

e. Transverse cracks on $45^{\circ}$ with the trailing edge (Error! Reference source not found.-c) are found in turbine blades together with the repeated TCs (Error! Reference source not found.-b). The main cause of these transverse cracks could become clear if the lay-up of reinforcing fiber layers is known. The outer layer (under the gelcoat) is usually randomly oriented, while the next 2 or four layers are most probably arranged at $45^{\circ}$ and $-45^{\circ}$ with the blade length. The cosmetic finishing machining processes may lead to some thinning, so that the subsequent layers $\left(45^{\circ}\right.$ and $\left.-45^{\circ}\right)$ become nearer to the surface. Vibrations (due to turbine stall) or fatigue loading may weaken the fiber matrix interface and lead appearance of such short cracks.

The distribution of the different TCs sizes on the blade length (normalized rotor radius) is shown in Error! Reference source not found.. It is clear that the short root cracks are mainly in the $100 \mathrm{~kW}$ turbine blades. Some TCs with a crack length of 5 $\mathrm{cm}$ are found mainly in $300 \mathrm{~kW}$ turbine blades.

\section{Edge damages}

Edge damages as edge cuts or crushing are observed at various positions along the trailing edge of the blades. Error! Reference source not found.-a shows an example of $10 \mathrm{~cm}$ edge cuts in the blade trailing edge of the $300 \mathrm{~kW}$ wind turbines, at about $3.4 \mathrm{~m}$ from the tip. On the other hand edge crushing (Error! Reference source not found.-b) can be found in both 100 and $300 \mathrm{~kW}$ rotor blades. The trailing edge in the $300 \mathrm{~kW}$ wind turbine blade is quite sharp, therefore any mechanical interaction with a hard body can result in such type of damage. This mechanical interaction may also arise from the impact of the crane lifting basket during transportation, maintenance or washing of the blades.
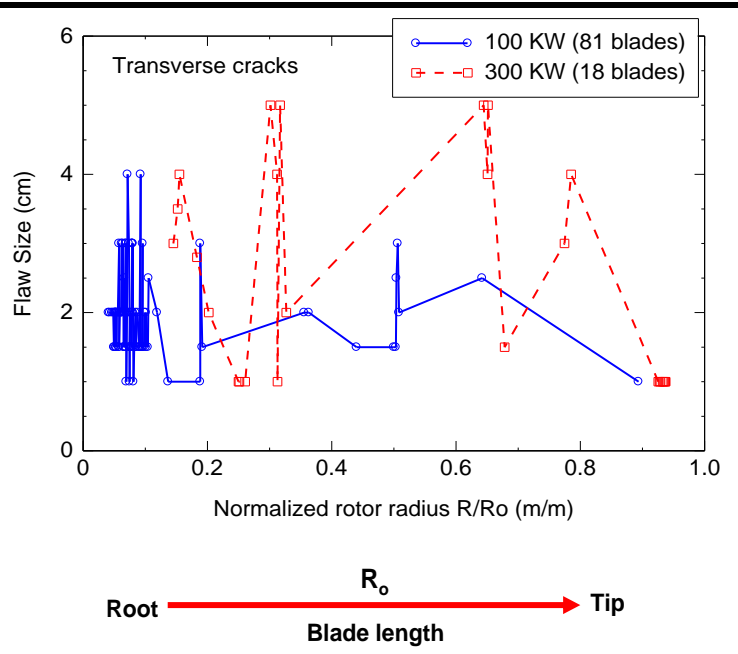

Figure 9 Distribution of the transverse cracks on the normalized rotor radius in 81 blades of $100 \mathrm{~kW}$ and 18 blades of $300 \mathrm{~kW}$ wind turbines.

Distribution of the edge cuts along normalized rotor radius is presented in Error! Reference source not found.. The edge damage size is in the rang 1 to 13 $\mathrm{cm}$. It can be observed that the edge cuts on the trailing edge of the $300 \mathrm{~kW}$ turbine blades are concentrated in the lower third of the blade, where the edge has very small thickness (reaching few millimeter). This reduces its resistance for crushing by impact of any outer forces.

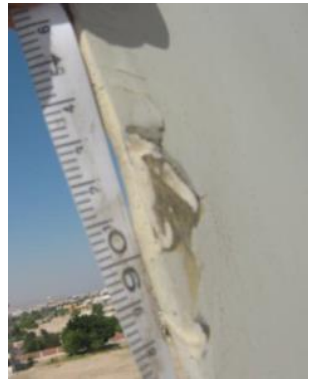

(a)

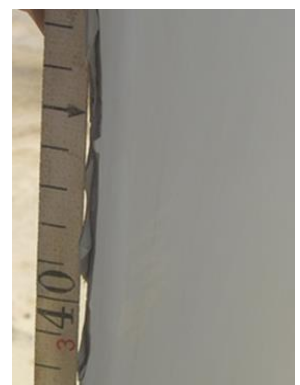

(b)
Figure 10 a) Edge cuts in a $300 \mathrm{~kW}$ rotor blade and b) crushing of the trailing edge of a $100 \mathrm{~kW}$ rotor blade.

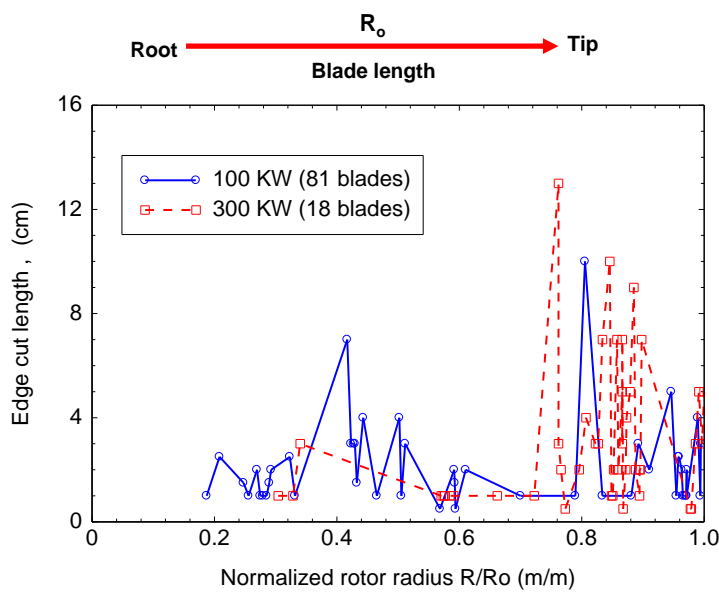

Figure 11 Distribution of edge cuts along the normalized rotor radius in 81 blades of $100 \mathrm{~kW}$ and 18 blades of 300 $\mathrm{kW}$ wind turbines.

\section{Surface and Coating Damages}

Coating damage includes hair line cracks, pin holes and penetrations in different sizes are observed on blade surface. 


\section{Hair line surface cracks}

Hair line surface cracks spread over areas with different sizes, and with random orientation or sometimes with a radial orientation trend from a certain point, as shown in Error! Reference source not found. $(\mathrm{a}-\mathrm{c})$. They are fine shallow cracks on the coating layer of the blade. For better identification of the hair line cracks, liquid penetrant test (PT) is used in some cases. An example for the hair line cracks detected by PT is shown in Error! Reference source not found.-c. In many cases hair line cracks are easily detected by VT, due to the contrast of the white gelcoat and the dark fine cracks, Error! Reference source not found.a-b.

Hair line surface cracks are located in different regions of blades in both 100 and $300 \mathrm{~kW}$ turbines, with different sizes as observed in Error! Reference source not found.. The size of the surface cracks is specified as the diagonal length of the cracked area, and is in the ranges of $2 \mathrm{~cm}$ up to $80 \mathrm{~cm}$.

The nature of the gelcoat layer or the existence of some external forces may be the causes of the hair line cracks. The gelcoat thickness ranges between 0.25 and $1 \mathrm{~mm}$ and in most cases it has a thickness of $0.6 \mathrm{~mm}$ [15]. Increasing the gelcoat thickness increases the probability of cracking, due to the hard nature of fiberglass reinforced plastic (FGRP). Also impacting the blade body by some external force [15], either during removing the product from the mold or during service can cause such gelcoat hair line cracks. It could finally conclude that the appearance of the hairline crack is due to a combined effect of the suitability of the gel coat to the working and environmental conditions.

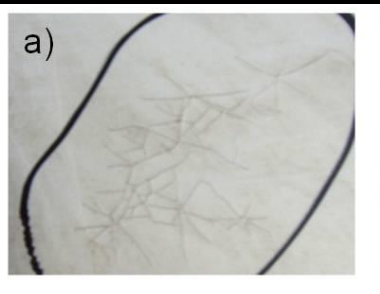

b)

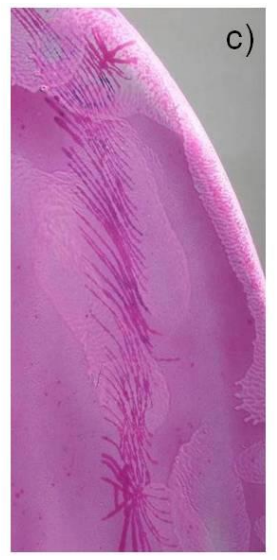

Figure 12 Hair line surface cracks found in blade of the 300 and $100 \mathrm{~kW}$ wind turbines, (a) and (b) detected by VT and (c) detected by PT

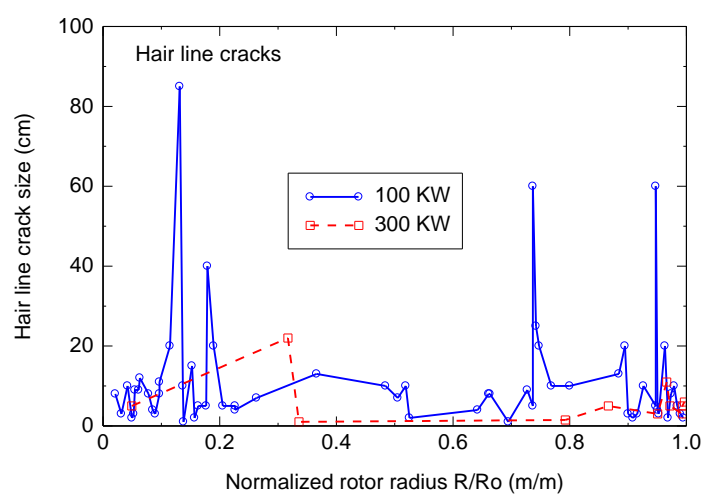

Figure 13 Distribution of the hair line surface cracks on the normalized rotor radius for 100 and $300 \mathrm{~kW}$ wind turbines.

\section{Pin Holes or Coating Pores}

Pin holes or coating pores are small pits in the coating layer of the blade with diameter of $\sim 1 \mathrm{~mm}$, Error! Reference source not found.-a. Smaller coating holes shown as orange peeling also found in various areas. Distribution of the pin holes along normalized rotor radius is illustrated in Error! Reference source not found.. Such pits are of different size areas with diagonals up to $30 \mathrm{~cm}$ and pore inter-spacing from few millimeters to $3 \mathrm{~cm}$. Moreover discrete pits with a diameter up to $2 \mathrm{~mm}$ are also observed as shown in Error! Reference source not found.-b. Such pores are distributed on the $100 \mathrm{~kW}$ blades, and over the lower half of the blade of the $300 \mathrm{~kW}$ turbines. This implies that the erosion of the blade with dust over the long service life ( 17 years) could be also another cause for formation of such small pin holes. Existence of such small pores increases the roughness of the blade surface and decreases the aerodynamic performance of the blade [11].

This type of discontinuity is expected in the coating layer during manufacturing as fine pin holes or orange peeling due to entrapped small air bubbles in the gelcoat [15] caused by some technical error concerning of the application distance of the pistol nozzle. 


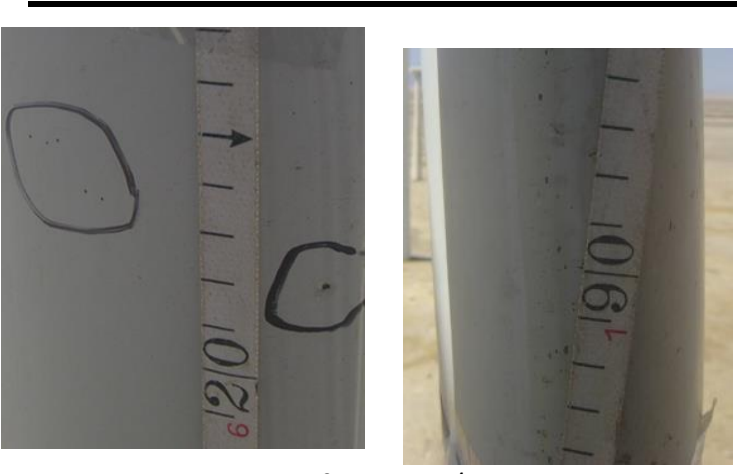

Figure 14 Examples of pin holes/coating pores.

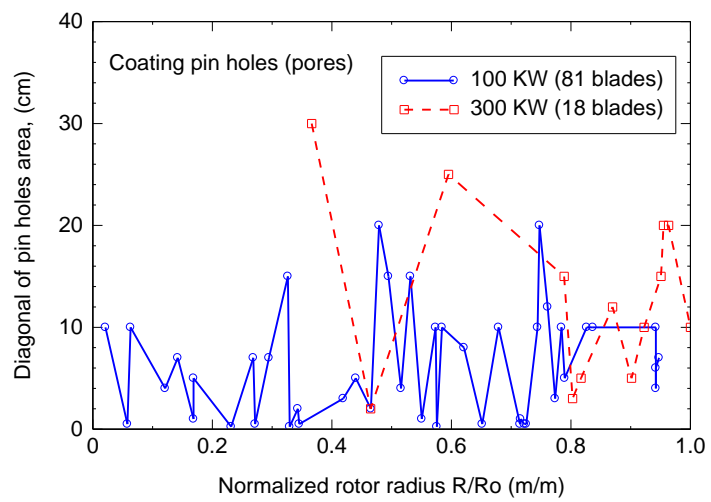

Figure 15 Distribution of coating pin holes (pores) along the normalized rotor radius in 81 blades of $100 \mathrm{~kW}$ and 18 blades of $300 \mathrm{~kW}$ wind turbines.

\section{Surface Damages}

Surface damage is the local removal of gelcoat. This type of discontinuity is found in different forms and sizes, either as rounded areas with a diameter from $2 \mathrm{~mm}$ to $7 \mathrm{~mm}$ such as the example shown in Error! Reference source not found..a, or as elongated to irregular areas up to $9 \mathrm{~cm}$ long on the leading edge, as shown in Error! Reference source not found. b-c.

The distribution of this surface damage over the blade length along rotor radius is shown in Error! Reference source not found.. Higher number of surface damages exists on the lower third of the leading edge of the $300 \mathrm{~kW}$ wind turbine blades, while nearly regular distribution of this coating damage towards the end of the aerodynamic section of the $100 \mathrm{~kW}$ wind turbine blades is found. Error! Reference source not found. $a-b$ indicates that, the coating layer thickness is more than $1 \mathrm{~mm}$. Decohesion of the gelcoat occurred frequently from the bonding materials of the two shell halves or which applied for some cosmetic reason to ensure good curvature of the leading edge. This can easily lead to cracking and separation of such hard thick material with repeated stresses. This damage can affect the inner blade structure even if the effect of climate change and weathering condition are difficult to assess [3].This coating damage needs cosmetic repair to cover the laminate structure from the environmental aging attacks, i.e. ultraviolet rays (UV), moisture and erosion.

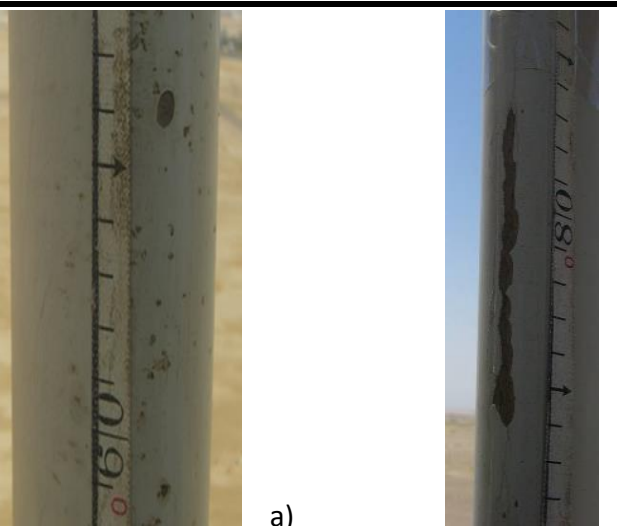

c)

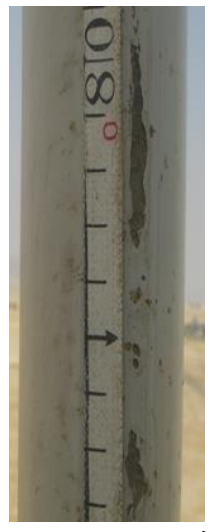

b)

Figure 16 a) Small surface damage and insect contamination, $\mathrm{b}$ and $\mathrm{c}$ ) extended surface damage.

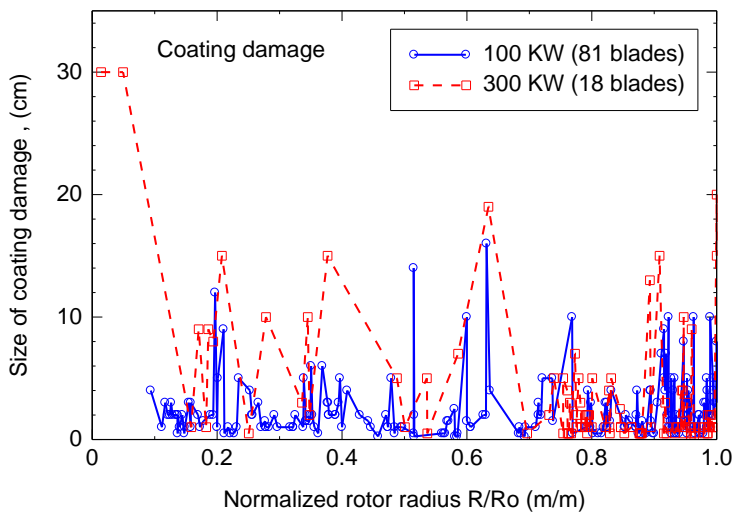

Figure 17 Distribution of coating damage along the normalized rotor radius in 81 blades of $100 \mathrm{~kW}$ and 18 blades of $300 \mathrm{~kW}$ wind turbines.

\section{Holes or Penetrations}

Holes or penetrations are pits of a clear depth through the blade material and have diameters of 3 to $30 \mathrm{~mm}$. Error! Reference source not found.-a,c shows some examples of penetrations found in the wind turbine blade. From the distribution of the holes along rotor radius in Error! Reference source not found., it can be observed that the holes are mainly concentrated near the tip of the blade either in the 300 or $100 \mathrm{~kW}$ wind turbines. Also, some holes spread along the blade. Some holes have a structural function such as the lower hole in Error! Reference source not found. -a, while the others appear during service. Error! Reference source not found.-c shows a hole with a depth of $12 \mathrm{~mm}$, which is probability originated during manufacturing as it is covered with gelcoat. Other penetrations could be due to mechanical interaction with external forces. 

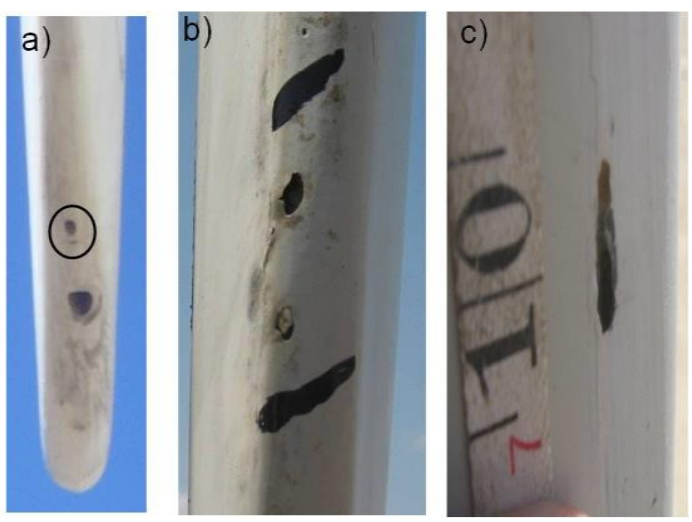

Figure 18 Holes (penetrations) in the leading edge of the rotor blades ( $a$ and c) 100 and b) $300 \mathrm{~kW}$.

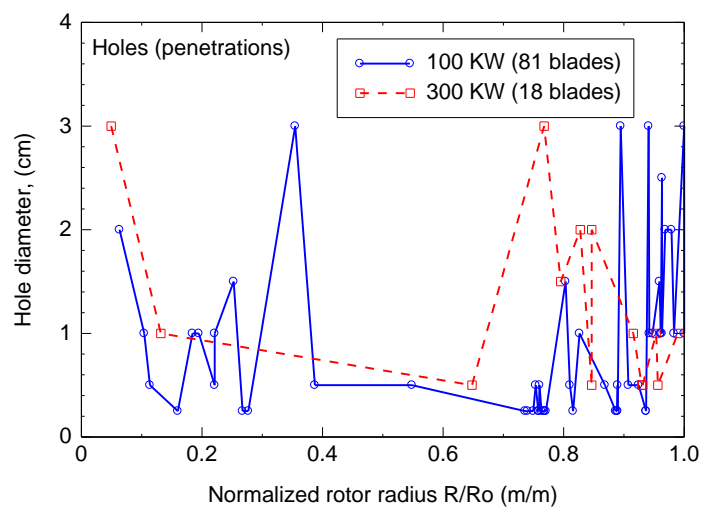

Figure 19 Distribution of holes or penetration on the normalized rotor radius in 81 blades of $100 \mathrm{~kW}$ and 18 blades of $300 \mathrm{~kW}$ wind turbines .

\section{Reworked Areas}

In addition to the above described surface damages, reworked areas are also investigated as illustrated in Error! Reference source not found.. Surface damages in repaired areas are caused by either untrained technicians or the use of unsuitable materials during the repair process. Error! Reference source not found. shows that the size of the reworked area ranges between $3 \mathrm{~cm}$ to $100 \mathrm{~cm}$ and is distributed over the blade length in the blades of $100 \mathrm{~kW}$ turbines, while little number of repaired areas are documented in $300 \mathrm{~kW}$ turbines near the tip. Many of the performed repairs need a cosmetic maintenance to improve their surface quality and consequently the aerodynamic performance of the blades.

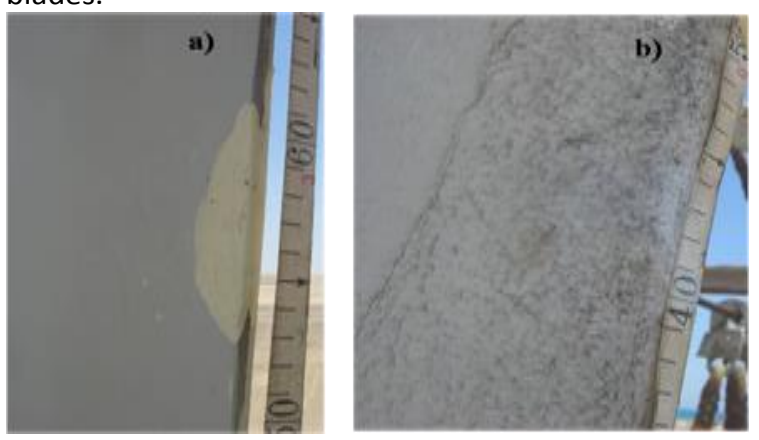

Figure 20 Examples of repaired (reworked) areas in the inspected wind turbine blades a) 100 and b) 300 $\mathrm{kW}$.

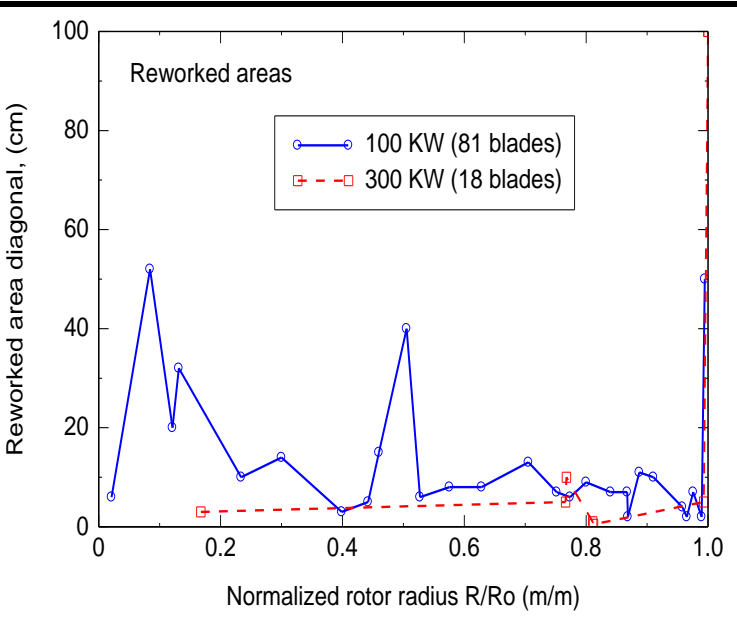

Figure 21 Distribution of reworked areas along the normalized rotor radius of the inspected blades.

\section{Conclusions}

From the current study the following conclusions can be drawn:-

- VT inspection is very practical method in detecting various discontinuities and damages in wind turbine blades. However, PT inspection is useful in revealing fine surface cracks.

- Various discontinuities and damages found in 81 blades of the $100 \mathrm{~kW}$ and 18 blades of the $300 \mathrm{~kW}$ wind turbines which have a life of 19 to 21 years are documented, analyzed and categorized into: 1) Transverse cracks, longitudinal cracks and surface cracks, 2) Edge cuts or crushing and side separation, 3) Surface or coating pores, surface damages, holes or penetrations, and 4) reworked areas.

- Longitudinal cracks with lengths up to $59 \mathrm{~cm}$ are found at geometric changes; i.e. in the root and the cover of the aerodynamic zone.

- Transverse carks are concentrated at the highly loaded region of the trailing edge of the upper third part of the blade.

- Edge cuts or crushing and partial side separation are mainly concentrated in the sharp trailing edge of the blades.

- Surface and coating damages are mainly on the leading edge of the wide surface area due to erosion by sand particles.

\section{References}

[1] J.C. Martin, A. Barroso, F. Parıs, and J. Canas, Study of damage and repair of blades of a $300 \mathrm{~kW}$ wind turbine, Energy 2008. 33 p. 1068-1083.

[2] D. Ancona, J. McVeigh. Wind Turbine - Materials and Manufacturing Fact Sheet, a report prepared by Princeton Energy Resources in International, LLC for the Office of Industrial Technologies. 2001. US Department of Energy.

[3] S.C. Pryor, R.J. Barthelmie, Climate change impacts on wind energy: A review, Renewable and Sustainable Energy Reviews, 2010. 14: p. 430-437. 
[4] Sabbah Ataya, Mohamed M.Z. Ahmed, Damages of wind turbine blade trailing edge: Forms, location, and root causes, Journal of Engineering Failure Analysis, 35 (2013) 480-488.

[5] P.E. Mix, Introduction to Nondestructive Testing, Second Edition, John Wiley \& Sons, Inc., New Jersey, 2005, p. 221. 2005

[6] Nondestructive Evaluation and Quality Control ASM Metals Handbook. 2nd edit ed. Vol. 17. 1992.

[7] C.W. Kensche, Fatigue of composites for wind turbines, International Journal of Fatigue, 2006. 28 p. 1363-1374.

[8] P. Albisser, Adhesives for bonding wind turbine blades, Reinforced plastics, 2009. Jan-Feb: p. 26-29.

[9] J.F. Manwell, J.G. MecGowan, and A.L. Rogers, Wind Energy Explained: Theory, Design and Application. 2nd Edition ed. 2009: John Wiley and Sons Ltd. 276304.
[10] H. Piggott, How to build a wind generator - the axial flux alternator windmill plans, University of Loughborough, UK, May 2003.

[11] D. Cripps, The future of blade repair, Reinforced plastics, 2011. 55(1): p. 28-32.

[12] Guidelines for Design of Wind Turbines. 2002, Denmark: Centraltrykkeri

[13] D. Hu, O. Hua, and Z. Du, A study on stall-delay for horizontal axis, wind turbine, Renewable Energy, 2006. 31: p. 821-836.

[14] J.W. Larsen, S.R.K. Nielsen, and S. Krenk, Dynamic stall model for wind turbine airfoils Journal of Fluids and Structures 2007. 23: p. 959-982.

[15] Technical trouble shouting guide for avoiding application defects of gelcoat in http://www.orgachim.bg/download/specs/smoli/en/ GELCOATS EN.pdf, accessed in 01.04.201 